\title{
Learning Environments Using Interactive Whiteboards: New Learning Spaces or Reproduction of Old Technologies?
}

\author{
Robyn Zevenbergen \\ Griffith University
}

\author{
Steve Lerman \\ London South Bank University
}

\begin{abstract}
Interactive whiteboards (IWB) are an innovation that is gaining considerable presence in many contemporary classrooms. This paper examines the use of IWBs in mathematics classrooms. Using a productive pedagogies framework to analyse classroom videos, it is proposed that the classrooms observed used a restricted approach in their use of IWBs. It was found that they were used for quick introductions to lessons and whole class teaching. They were also teacher directed and fostered shallow learning. Through interviews with the teachers, it was found that the approaches observed were based on assumptions about learners and technology.
\end{abstract}

In this paper, we explore the ways in which teachers use Interactive Whiteboards (IWBs) in mathematics classrooms. There is a sense that this tool may offer considerable potential to enhance student learning. Promoters of the tool provide case studies of the novelty and support that can be achieved through the clever use of the tool (Edwards, Hartnell, \& Martin, 2002). How this is enacted in classrooms is the focus of the analysis in this paper.

Drawing on the principles of activity theory to frame the analysis, we particularly use the notion of tools, in this case IWBs, which mediate pedagogic relationships. Within activity theory, tools can refer to both concrete and semiotic tools. As such, we draw on a range of tools that can be used to explain the complex milieu of classrooms and the uptake of IWBs. The values and beliefs which teachers hold about pedagogy and/or technology mediate the ways in which they will use such technologies. The beliefs and values may relate to the pedagogical approaches that are adopted or to the technological tools themselves. Where teachers hold particular views about how children best learn mathematics, then they are most likely to employ strategies that align with those beliefs. Similarly, if they see technology as a tool that can undertake particular functions (such as a calculator can be used for working out arithmetic tasks), then the technology will be used in that fashion. In exploring computer-mediated learning using activity theory, Waycott, Jones and Scanlon (2005, p. 107) reported that there is a reciprocity between the tools and the learner where "the user adapts the tools they use according to their everyday practice and preferences in order to carry out their activities; and how, in turn, the tools themselves also modify the activities that the user is engaged in." Using activity theory, we explore the ways in which IWBs were used in a number of classrooms, provide an evaluation of the approaches being used by teachers, and then seek to explain the observations that were made in these classrooms. 


\section{Interactive Whiteboards as Mediating Tools: A Background}

The implementation of interactive whiteboards in schools in the UK has been strongly supported by the government (Beauchamp, 2004) with over $£ 50 \mathrm{~m}$ being spent on their implementation in primary and secondary schools (Armstrong, Barnes, Sutherland, Curran, Mills, \& Thompson, 2005). However, it has not received the same fiscal support in Australian schools. Many schools are supporting the implementation of these devices through various means but without systematic support. In most cases, the implementation of IWBs is a school-based decision and as such is supported by funds raised by the schools. How the IWBs are implemented within a given school is dependent upon the resources of the school to provide the equipment and the beliefs of the teaching staff as to the value of the tool. As such, there is considerable variation across Australia as to their uptake and implementation. This can range from how IWBs are placed in classrooms (who has them and where they are physically located); how teachers use them; and access to professional development.

\section{Teachers, Professional Development and Implementation}

In considering the ways in which IWBs have been taken up by schools as a tool for enhancing student learning, the implementation of technology such as the IWBs is not without considerable investment of both human and economic resources. Without considerable investment of time, energy and money, reforms can fail in their realisation. As with any change process, the implementation of interactive whiteboards is met with those who embrace new forms of technologies juxtaposed with those who resist such reforms. For example, Glover and Miller (2002) reported that their experienced teachers were skeptical of these new forms of pedagogy while, in contrast, pre-service teachers saw these new technologies as an integral and valued component of their future practice. Drawing on socio-cultural perspectives to the use and uptake of mediating technologies - in this case IWBs, Armstrong et al. (2005) suggest that there is a tendency for teachers to use IWBs as "an extension of the non-digital whiteboard" (p. 458). Beauchamp (2004) argued that the transition from traditional modes of teaching to the totally integrated use of IWBs in classrooms demands a shift in pedagogical style of the teacher. In the process of moving from the novice user to one who integrates the IWB into their repertoire of pedagogic skills, Beauchamp contends that there needs to be a considerable investment for teachers to learn to develop their technical competence alongside their pedagogical skills. These twin aspects of IWB usage are critical to the repertoire of skills needed by teachers if they are to become synergistic users of IWBs.

For teachers to realise the potential of IWBs, Glover and Miller (2002) contend that teachers need to recognise that there is considerable interactivity associated with the use of IWBs. They argue that the IWB can engender an approach that fails to radicalise pedagogy where the IWB is used to enhance students' motivation rather than become a catalyst for changing pedagogy. In 
supporting teachers to adopt approaches that enhance interactivity with IWBs, Armstrong and colleagues employed a collaborative, long term project where teachers and researchers researched with the teachers on aspects of their pedagogy.

The extension of the computer through the use of IWBs creates new opportunities as well as obstacles to learning. To be competent with the use of IWBs, it was recommended that teachers need daily access to such tools (Armstrong, Barnes et al., 2005) so that teachers are able to develop their repertoire of skills and to integrate it into practice (Glover \& Miller, 2001). In studying the use of IWBs in English classrooms, it was reported that:

IWB can facilitate and initiate learning and impact on preferred approaches to learning. The pupils describe how different elements of software and hardware can motivate, aid concentration, and keep their attention. On the negative side, pupils candidly describe their frustration when there are technical difficulties, their desire to use the board themselves and their perceptions of teacher and pupil effects. (Wall, Higgins, \& Smith, 2005 p. 851)

Greiffenhagen (2000) argued that the availability of IWBs as a teaching aid is only of value where it becomes part of the regular pattern of classroom life. Others argue that teachers also need to have access to a wide range of software and applications that are subject specific (Armstrong et al., 2005) and that on-going training with the use of IWBs helps teachers develop their skills and knowledges with regard to the affordances of these tools.

\section{Students, Learning Environments and IWBS}

In their study of the uptake of IWBs in a secondary school, Glover and Miller (2001) proposed that IWBs offered considerable benefits to learning. They reported that students were more likely to engage in learning due to the surprise element that was offered through the IWB, the large visual cues offered through the IWB presentation format, and the quicker pace of lessons. In exploring the impact of IWBs on students' thinking, Wall and colleagues (2005) reported that, among other things, students indicated that there was considerable motivational effect of the IWBs to the extent that IWBs could change students' perceptions of subject areas. In the research undertaken by Wall et al. mathematics was the cited example. While this study showed positive effects of IWBs on students' thinking, the study also noted student (and teacher) frustration with technology not functioning and their unrealised desires to engage with the IWBs themselves.

As a teaching tool, IWBs have considerable potential to change interaction patterns. In their study of classrooms - both literacy and numeracy in IWB and non-IWB classrooms - Smith, Hardman and Higgins (2006) found that there is a faster pace in lessons using IWBs than non-IWB lessons; that answers took up considerably more of the overall duration of a lesson; and that pauses in lessons were briefer in IWB lessons compared with non-IWB lessons. They also reported a faster pace in numeracy lessons than in literacy lessons. While they reported 
some support for the potential of IWBs, they concluded that overall the use of IWBs was not significantly changing teachers' underlying pedagogy. The majority of teacher time was still spent on explanation and that recitation-type scripts were even more evident in IWB lessons. They found that while the pace of the lessons increased, there had been a decline in protracted answers from students and that there were fewer episodes of teachers making connections or extensions to students' responses.

While there is a suggestion that IWBs have considerable potential to change interactions and modes of teaching, this has not been found to be the case in practice (Smith, Hardman, \& Higgins). These authors claim that although there is a faster pace in lessons, less time is being spent in group work. There is a tendency for teachers to assume a position at the front of the class when using IWBs (Maor, 2003). Similarly, Latane (2002) suggests that there needs to be a move from teacher-pupil interaction to one of pupil-pupil interaction. In studying mathematics classrooms, Jones and Tanner (2002) reported that interactivity can be enhanced through quality questioning. In other words, the quality of the questions posed and the breadth of questioning needs to be developed to ensure interactivity in mathematics teaching when using IWBs.

Research has shown that IWBs may offer potential links between learning styles of students and the learning environment offered through the IWB format (Glover \& Miller, 2002). In their review of the literature on IWBs, (Glover, Miller, Averis, \& Door, 2005), a range of curriculum areas was reported as having adopted the IWB as part of their pedagogy and links to learning styles. However, in another study (Schmid, 2006) it was reported that some students did not like the openness of their responses as they were available to public scrutiny and students felt threatened by that openness and hence less likely to participate. However, other students reported that the use of technology helped to create a community within the classroom where they could expose their difficulties to the group and seek the support of others in solving problems.

Overall, there is considerable diversity in the studies conducted on IWBs. There is a sense that there is considerable potential in the tool but this has not been realised. There are concerns about the reduction in interaction, the increase in teacher control, and the faster pacing of lessons which are often at the expense of quality questioning. Within this context, we sought to identify the ways IWBs were being used in classrooms that were part of a much larger project on the use of ICTs in mathematics classrooms.

\section{Data Collection}

The research reported here compares data collected as part of a larger study (Lerman \& Zevenbergen, 2006a) with subsequently collected data on teachers' use of IWBs. In this paper, we present the analysis of classroom lessons using a particular framework. A total of nine schools participated in the study. Over the three years of data collection, some schools dropped out of the study, and others came in. Five schools remained in the study for its duration. Purposive sampling 
techniques were used in the selection of schools. The schools were selected on their representativeness of the diversity found in Australian schools in terms of social groupings being served (high, medium and low socioeconomic status), geographical location (city, rural, remote); technology implementation (high or medium; integrated into classroom, computing laboratories); and school structure (single age classes, multi-age classes). Classrooms from the upper primary sector were involved in the data collection.

The participating schools were provided with a video camera to capture those lessons where they used computer technology to support numeracy learning. As the data collection could not be programmed by teachers, it was recognised that a method was needed that would cater for the flexibility in teaching programs. While this method created some difficulties for teachers to coordinate data collection, the research team also offered to video lessons if requested. This offer was taken up by a number of the teachers. At the commencement of the project, IWBs were not part of the participating schools' technological resources but as the project progressed, one school implemented the IWBs and another school joined the project. This latter school had been using IWBs for a number of years prior to coming into the study and marketed themselves as a highly innovative school in terms of technology use. In both schools, all classes were using IWBs as part of their practice. In analysing the data, we have kept the video data where teachers used computers to support numeracy learning separate from those lessons where IWBs were used. In part this was a decision made on the basis of different forms of technologies. However, the video data where teachers used IWBs is much shorter in duration than that where ICTs were used. As such, it appeared that a very different pedagogy was being used by teachers when using IWBs than when they used ICTs.

The data presented in this paper represent only one aspect of the project. In this paper, we present one of the ways in which we sought to have some measure of the types of pedagogy being used in classrooms where ICTs were being used to support mathematics learning. Using a well-tried method to analyse pedagogy, we adopted this approach to analyse the ways in which pedagogies were adopted in the participating classrooms. For this paper, we present the data as a whole. For us, what was a significant point of interest was the way in which pedagogies were used to support interactive whiteboards compared with ICTs. Our observations of lessons and the video data suggested that there were quite different approaches being used so we sought a rigorous framework through which we could draw some comparisons.

For the data presented in this paper, we draw on the analysis of 45 classrooms using ICTs and 15 classrooms using IWBs. These data have been collated across the schools so that the independent variable is whether the classroom used IWBs or not. We do not intend to draw any further inferences from the data based on school type or other variables in this paper. Our primary emphasis is on the pedagogies being used in ICT-based lessons and IWB lessons. 


\section{Descriptive Analysis of Pedagogy}

Two analyses were conducted on the video data. In the first instance, a running record was taken of the lesson with a transcript developed of the lesson. This record consisted of both description of the lesson and the interactions between teacher and students. This is a relatively traditional method used to make sense of classroom actions. Our data confirm that of Smith, Hardman, and Higgins (2006) where we could observe the level of questioning being used by teachers in these lessons. It was of a lower level format where teachers were asking more recall questions than those requiring deeper levels of understanding. This type of questioning also allowed for a quicker pacing of the lesson since teachers were able to ask quick fire questions where there was little depth in the responses required.

The predominant approach used by teachers when using the IWBs was that of whole class teaching. In these settings, the teacher controlled the lesson, inviting students to participate in manipulating the objects. In all cases, only one child was involved in such manipulations at any one time. The remaining students sat on the floor or at their desks. However, in observing the students, there were very few behavioural issues one would expect to see when children are seated for such lessons, and that they were predominantly focused on the teacher talk and actions. This observation was consistent across the lessons and schools and suggested that even though the lessons were whole class and teacher led, the students appeared to be engaged with the lesson.

In all cases, the teachers used the IWBs as the introduction to the lesson. Typically, the orientations with the IWBs were between 5-15mins and were used to orientate the students to the topic that would then be followed. The introduction was whole class with quick pacing. In some cases the teachers used pre-existing lessons that had been developed by other teachers and were available through the resources. In other cases, they used the tools (such as fractions, calculator, or clocks) that came with the IWBs. In all cases, they used the resources that were part of the packages supplied with the board. Once the students had been involved in the introductory component of the lesson, they returned to their desks to work on activities related to the topic being introduced.

Depending on the resources used by the teacher, there were instances where the IWB made possible a rich introduction to aspects of mathematical language. For example, in one lesson the teacher was using the fraction tool in which a shape (circle, rectangle and square), chosen by the teacher, was used to represent various fractions. These could be shown in a variety of ways such as pies in the case of circles or through horizontal, vertical grids on rectangles and squares. Through the ease with which the shapes could be selected and in how they were represented, the teacher was then able to draw on a repertoire of language to discuss the shapes, representations and fractions. The ease and speed at which shapes and denominators could be selected enabled a lot of talk/questions about the numbers being represented. As with other lessons, the speed of questions and delivery meant for fast pacing. However, there was little or no evidence of deeper probing of concepts or for mathematical thinking in terms of drawing patterns across the experiences. In the lesson on fractions, for example, while students 
were presented with a range of fractions (halves, quarters, thirds, sixths, eighths, tenths), these were simply representations of denominators and with different numerators being used. In some cases, equivalence was discussed. For example, $4 / 8$ was talked about as being equivalent to ?. However, this discussion was only undertaken when the 4 shaded pieces were adjacent so that it clearly represented ?. The discussion did not occur when it was possible for the 4 segments to be scattered. Similarly, there was no discussion about the relationship between the size of the segments and the number in the denominator; that is, the inverse relationship between the segment and number. So while the students were exposed to a range of experiences, the richness of the mathematics was not being drawn out of the lessons.

\section{Productive Pedagogies Analysis}

While the observations provided us with some indicators of how the IWBs were being used in the classroom, we also employed a quantitative measure to document the use of IWBs. This measure allowed us to more rigorously analyse the lessons. We have used this approach in analysing the use of ICTs in classrooms (Lerman \& Zevenbergen, 2006) so were able to compare those data against the use of IWBs. The approach was used extensively in the Queensland Schools Longitudinal Reform Study (QSLRS) (Education Queensland, 2001) and through that process has been validated as an adequate tool for analysing classroom practice. The process involves three observers observing the lessons which had been videotaped. Each observer rates the lesson against nominated criteria at the completion of the lesson and the score is for the overall lesson. If there is some evidence of a criterion in the opening phase of the lesson but does not appear again, then this means that it was not a strong feature of the overall lesson. The three observers rate their observations independently and then come together to come up with a common score. This involves a process of negotiation to arrive at the common outcome. In most cases, there was usually a difference of 1 between the ratings and the ensuing discussion meant that the observers needed to negotiate their ratings with the other two.

For the framework we have used the work of the QSLRS (Education Queensland, 2001) in which the researchers analysed one thousand lessons in terms of the pedagogies being used by teachers. The method was that described above and where the criterion for each rating was based on the Productive Pedagogies. There are four dimensions within the framework - Intellectual Quality, Relevance, Supportive School Environment and Recognition of Difference - in which there are a number of pedagogies that are evident of that theme. The four dimensions are based on particular aspects of teaching quality which were drawn from the theoretical work of Newmann and associates (1996) which sought to identify the quality of learning, in terms of knowledge and environment. In each of the four dimensions, other identified aspects of pedagogy were identified. The dimensions enabled the clustering of pedagogies around nominated themes. These can be seen in Table 1. 
Table 1

Productive Pedagogy Dimensions, Items and Key Questions (from Gore, Griffiths, $\mathcal{E}$ Ladwig, 2006)

Productive Pedagogy Key Question

Intellectual quality

Higher order thinking

Are higher order thinking and critical analysis occurring?

Deep knowledge

Does the lesson cover operational fields in any depth detail or level of specificity?

Deep understanding Do the work and response of the students provide evidence of understanding concepts and ideas?

Substantive conversation

Does the classroom talk break out of the initiation/ response/evaluation pattern and lead to sustained dialogue between students, and between students and teachers?

Knowledge as

problematic

Are students critiquing and second guessing texts, ideas, and knowledge?

Meta-language

Are aspects of language, grammar and technical vocabulary being foregrounded?

Relevance

Knowledge integration

Does the lesson range across diverse fields, disciplines and paradigms?

Background knowledge Is there an attempt to connect with students' background knowledge?

Connectedness to

the world

Do lessons and assigned work have any resemblance or connection to real life contexts?

Problem based curriculum Is there a focus on identifying and solving intellectual and/or real world problems?

\section{Supportive School Environment}

Student control

Social support

Engagement

Explicit Criteria

Self regulation

\section{Recognition of Difference}

Cultural knowledges

Inclusivity

Narrative

Group Identity

Citizenship
Do students have any say in the pace, direction or outcome of the lesson?

Is the classroom a socially supportive, positive environment? Are students engaged and on-task?

Are criteria for student performance made explicit?

Is the direction of students' behaviour implicit and selfregulatory?

Are diverse knowledges brought into play?

Are deliberate attempts made to increase participation of all students from different backgrounds?

Is the teaching principally narrative or expository?

Does teaching build a sense of community and identity?

Are attempts made to foster active citizenship? 
In undertaking the ratings, scores were given for the evidence of a particular pedagogy. These scores ranged from zero where there was no evidence of the pedagogy through to 5 where the pedagogy was an integral part of the lesson. For each criterion, descriptors were developed within the original model so as to enable standard assessments to be made across researchers and classrooms. Thick descriptions were also developed for each pedagogy so that there was a common understanding developed among observers as to what was being observed. These protocols were used in this study.

Within the Productive Pedagogy approach, there is a strong emphasis on raising the quality of teaching in terms of intellectual experiences and social learning. The outcomes of the QSLRS (Education Queensland, 2001) indicated that teachers were very good at providing a supportive learning environment but that the intellectual quality was quite poor. When the analysis was undertaken across key learning areas, it was reported that the learning environments in mathematics scored the least favourably suggesting that the intellectual quality and social learning in mathematics (across all years of schooling) was poor.

In seeking to explore the use of IWBs in mathematics classroom, we undertook the same analysis of the classroom videos in the 9 schools. As can be seen in Table 2, the scores are low in most areas. We have included the analysis of classroom data where ICTs were used in mathematics classrooms as a comparison. We will also use the base data from the QSLRS as a standard against which to compare the general scores of productive pedagogies in mathematics classrooms. As noted previously, the data that we have collected for the ICT classrooms was not surprising as it aligned with the QSLRS data for mathematics classrooms. It was not the intention of this study to observe non-ICT classrooms so no comparisons were sought for non-ICT classrooms.

These data indicate that when using the IWBs as a pedagogical device, their effectiveness may be somewhat limited. We have reported the data for when teachers used ICTs to support numeracy learning elsewhere (Lerman \& Zevenbergen, 2006) and this showed very low levels of quality learning potential. However, when using the same framework to analyse the use of IWBs, we note some significant differences where the IWB pedagogy was scored much lower than when using ICTs. Generally speaking, the 20 ICT outcomes were rated as superior to those obtained with IWBs. These data suggest that across the 20 pedagogies, the IWB methodology was particularly poorer in relation to the following seven dimensions (i.e. these group differences were statistically significant using a $t$ test) - problem-based curriculum; knowledge integration; description; academic engagement; self regulation; explicit criteria; and social support.

From these data we can conclude that the use of IWBs in this study actually reduces the quality of mathematical learning opportunities; provides fewer opportunities for connecting to the world beyond schools; and offers little autonomous/independent learning opportunities for students. This suggests that the current use of IWBs may not be providing opportunities for deep 
learning in mathematics classrooms. While these data are alarming in terms of their low scores, we sought to understand the phenomenon noted earlier in this paper. While the low scores would suggest that there was potential for low levels of mathematical learning, our observations of the lessons indicated that despite these perceived low scores, there were few behaviour problems with students. Students sat on the floor or in desks and were engaged by the technology. After these scores were obtained and analysed, we returned to the schools and interviewed teachers to seek some explanation of the findings.

Table 2

Productive Pedagogy Analysis of IWB use in Upper Primary Clasrooms

\begin{tabular}{|c|c|c|c|c|c|}
\hline \multirow[b]{2}{*}{$\begin{array}{l}\text { Dimension of Productive } \\
\text { Pedagogy }\end{array}$} & \multicolumn{2}{|c|}{$\mathrm{ICT}$} & \multicolumn{2}{|c|}{ IWB } & \multirow[b]{2}{*}{$t$} \\
\hline & $\mathrm{M}$ & $\mathrm{SD}$ & M & $\mathrm{SD}$ & \\
\hline Depth of knowledge & 1.70 & 1.33 & 1.47 & 0.92 & -0.62 \\
\hline Problem based curriculum & 2.22 & 1.33 & 0.93 & 0.59 & $-3.60^{* *}$ \\
\hline Meta language & 1.70 & 1.05 & 1.33 & 0.62 & -1.26 \\
\hline Background knowledge & 1.80 & 1.13 & 1.60 & 0.63 & -0.67 \\
\hline Knowledge integration & 1.50 & 1.28 & 0.53 & 0.64 & $-2.81^{*}$ \\
\hline Connectedness to the world & 1.39 & 1.41 & 0.73 & 1.03 & -1.67 \\
\hline Exposition & 1.13 & 1.59 & 0.73 & 0.80 & -0.93 \\
\hline Narrative & 0.37 & 0.93 & 0.20 & 0.41 & -0.68 \\
\hline Description & 2.33 & 1.04 & 1.40 & 0.63 & $-3.26^{* * *}$ \\
\hline Deep understanding & 1.43 & 1.44 & 1.20 & 0.68 & -0.61 \\
\hline Knowledge as problematic & 1.15 & 1.44 & 1.13 & 0.74 & -0.05 \\
\hline Substantive conversation & 1.22 & 1.36 & 0.53 & 0.74 & -1.85 \\
\hline Higher order thinking & 1.30 & 1.52 & 1.20 & 0.77 & -0.25 \\
\hline Academic engagement & 2.22 & 1.33 & 1.47 & 0.83 & $-2.05^{*}$ \\
\hline Student direction & 0.74 & 0.91 & 0.40 & 0.63 & -1.34 \\
\hline Self regulation & 3.26 & 1.12 & 2.2 & 1.32 & $-3.04^{* *}$ \\
\hline Active citizenship & 0.28 & 0.75 & 0.07 & 0.26 & -1.09 \\
\hline Explicit criteria & 2.83 & 1.22 & 1.27 & 0.96 & $-4.52^{* * *}$ \\
\hline Inclusivity & 0.30 & 0.73 & 0.07 & 0.26 & -1.24 \\
\hline Social support & 2.48 & 1.21 & 1.27 & 0.59 & $-3.73^{* * *}$ \\
\hline
\end{tabular}

Note. ${ }^{*} p<0.05 .{ }^{* *} p<0.01 .{ }^{* * *} p<0.01$. 


\section{Activity Theory: Coming to Understand the Use of IWBs}

Activity theory arises from the work of Vygotsky (1978, p. 40), and captures both the mediating role of culture in all human experience and also the goal orientation of all activity. Leont'ev's (1981) development of activity theory emphasised further the goal orientation and focused in particular on its different aspects: operations, actions, and activity. More recent iterations of activity theory draw on Engeström's second generation framework (e.g., 1999, p. 31) where the mediating tools were extended and elaborated substantially to identify the participants and resources present in an activity, and their different roles and responsibilities. His elaborate representation of these elements and their connections enables an identification of tensions and contradictions in activity systems and hence the potential for development. His model of activity is represented in Figure 1.

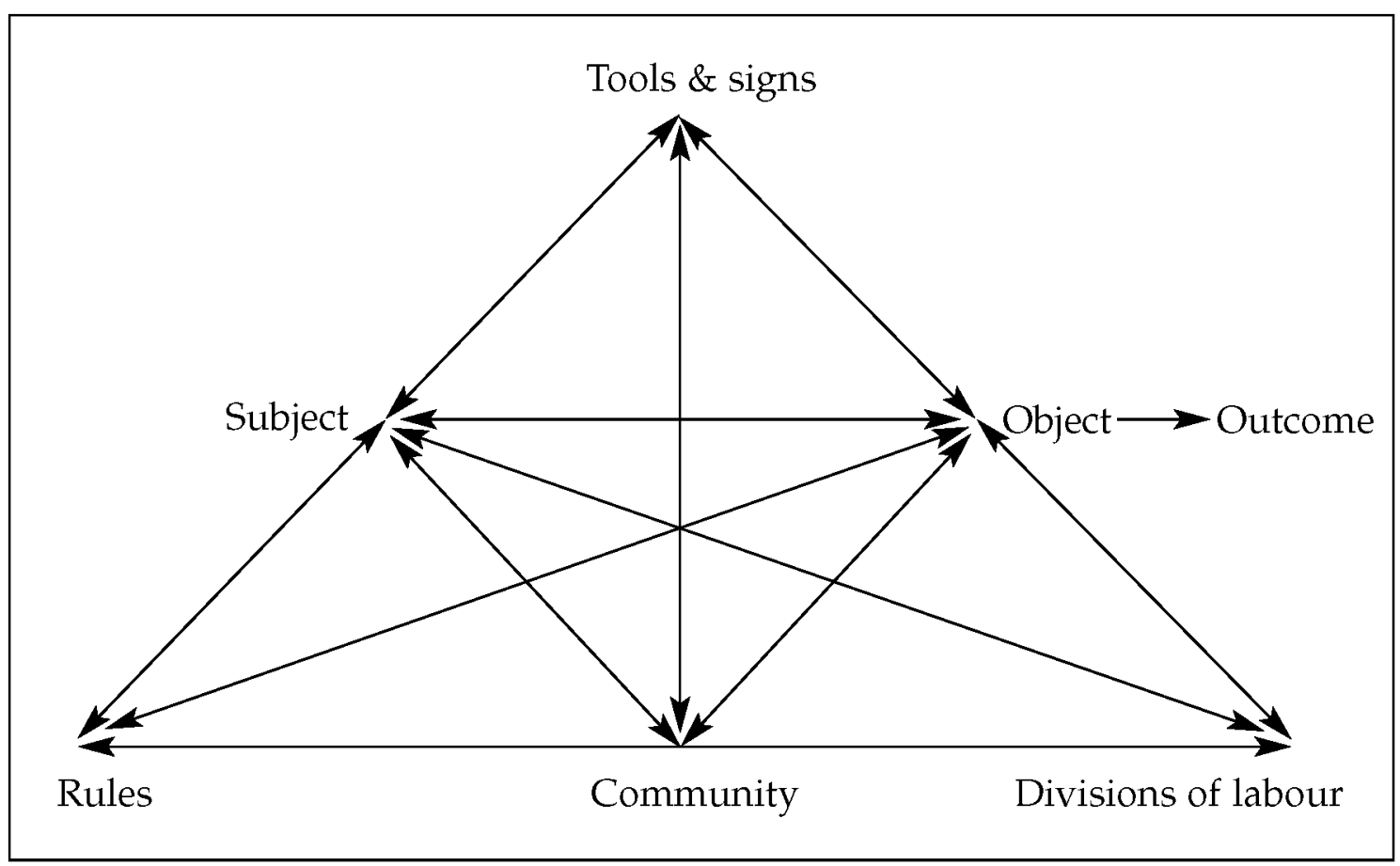

Figure 1. Engeström's second generation activity theory.

The model proposed by Engeström extends the work of Leont'ev so as to consider not only the tension and contradiction between points in the framework but also considering the context within which learning occurs. For us, the theory allows us to consider the results we have observed in relation to these tensions. In the following sections we draw on the third generation activity theory to help theorise the outcomes noted in this study. 


\section{Artifact}

Within activity theory, signs and tools mediate learning so, in our case, the IWBs were seen as artifacts that shape the ways in which learning can occur. The teachers found the resources that were available through the IWB, such as preplanned lessons and digital tools (protractors, rulers, and so forth), offered different ways of working with the students. Not only were the resources shaping the ways in which teachers taught and planned, they impacted on other aspects of their work.

Shane: I find that there are a whole lot of really good lessons that I can just use. If I am doing something on area for example, there are lessons already made up. Some other teachers have developed them so they have to be good ones. I am sure that the company only puts up the best examples. I have found these to be very handy and they save me doing the preparation work. I guess I change them a bit to suit me and the kids but they are pretty much there.

Most of the teachers had some comment about the time factor in the use of IWBs. It was seen to save preparation time in two different ways. As evident in the comment above, Shane drew on the resources that had been made by other teachers as these were 'tried and proven' examples of lessons that worked. In observing his lessons, we noted that he would select from the databank and then implement the lesson. Another teacher commented on how, when using the IWB, the toolkit meant that the resources were all in the one place so she did not have to hunt around for them. Knowing that the protractor, ruler, clock, calculator were all on the screen and at the touch of the board, was seen to be a considerable timesaver. Other teachers made similar comments about the tools that were available on the IWB:

Jemima: I think the whiteboard is a great resource. You have the tools there on the board, you just need to click and they are there.

Sarah: I think that the tools on the whiteboard are just great. They are done in a way that the children like them. When I pull up the calculator, for example, it looks exciting. It is much more interesting than the overhead projector type. I think that these kids expect a bit more from their computers and this is possible with the interactive whiteboard.

These built-in tools were seen to help teaching by reducing time spent on preparation of lessons but also within the lesson. This helped to make for a quicker pacing of lessons. The quicker pace was seen to enhance learning opportunities by engaging students. When using the IWBs, it would appear that the teachers were aware of the faster pace of the lessons. Having the ready-made 
resources available meant that little time was 'wasted' moving from one site to another or drawing representations on the traditional boards or papers. They articulated that they posed a lot more teacher questions and the students had greater opportunities for participating in the lessons due to the increased questioning.

Maxine: One of the things that I like about the whiteboards is that I can ask a lot more questions. You just have to click on the menu and there is the lesson or the things you need so you are not wasting a lot of time putting up overheads or drawing things on the board. I can ask more questions to the kids to see what they know and to get them to think about things. Like when we did the lesson with the clocks. You just click on the clock and there it is. You can just move the time around as quick as the kids respond. I think they like the quicker speed. They seem to enjoy the race of the lesson. If they answer quickly, then we can do another one or something a bit different.

The IWB offers other potentials that were not possible in previous media. In the following observation of a lesson, we were able to see how the accuracy of the IWB makes the teaching of fractions possible in new and novel ways.

While the teacher poses the questions, these are teacher-initiated questions and tend to be of a low level- that is, recall-type questions. Observing a lesson on fractions, the teacher had used the fraction creator. In this, the teacher used the circle and made various numbers of segments. With each new model of fractions, she posed questions including "How many pieces are there?" "What fraction is that?" The pacing of questions was faster than would be possible if the teacher were to draw the objects on the board and then create sections. What was possible in this format was that the accuracy of the sections made for less confusion as to the size (and hence equality in those sizes) but also made possible the more difficult representations (such as sevenths or fifths). (Lesson Observation)

However, while the accuracy of representation was a strength of the IWB, it is noted that the overall pedagogy remained similar to most lessons we have observed in the more traditional modes of teaching. The depth of questioning remained at a relatively superficial level where low levels of questions were posed. Thus, there remained considerable tension in what was offered and what could have been asked. While some aspects of pedagogy had changed, others had remained in place.

One of the observations in the use of IWBs was that it seemed to be used for the introduction to the lessons. In following this observation, teachers were asked if this was the case and if so, why. In the interviews, it was confirmed that the teachers tended to use the IWB to orientate the lesson and to motivate the students. 
Heidi: I use it to get the lesson started. The kids are all together, they are all on the one task, they know what we are doing. That is a good way to start the lesson. It is also good as the kids are very motivated by the boards so they are keen to get into the lesson.

In examining the role of the artifact one must also ask what it is replacing, both physically and in how it is used during teaching. The IWB largely replaces the standard whiteboard in that whilst it is also available for pupils to be called to the board to present their ideas, proposals, and outcomes of their problem solving, it can also be used to present content previously prepared and it enables the teacher to choose high quality accurate representations as they are called for during the progress of the lesson. The IWB enables the same variety of font formats and other visual effects as word processing packages.

In most classrooms the whiteboard remains on the wall alongside the IWB. There is some sense that the students in classrooms expect a higher level of digital media in their lives. Following one lesson where the teacher had been working with some number work and using the calculator, we discussed the approach and what was offered through the IWB environment that would not be possible with the non-digital environments. In the case being observed, it was posed that the same learning could have occurred had the teacher used the traditional whiteboard and an overhead projector which would have been a substantially cheaper option. The teacher commented:

Marcie: What I think is the key to this is that the calculator is already there. I click it on and there it is. I don't have to walk to the OHP and use that medium. There is no time being wasted. The calculator (on the IWB) is a neat one and the kids like it. I think that they are so savvy with technology that they come to expect that, you know, the instant appearance of things - like the calculator. They get turned off by wasting time moving around, they like things to come up at the touch of a key. They just expect it, they have grown up with computers and they just expect that that is the way the world is.

The overhead projector (OHP) can be used to project pre-prepared transparencies onto the whiteboard but in our experience in these schools the $\mathrm{OHP}$ is rarely used. Our observations indicate the predominance of the latter two uses of the IWB, pre-prepared materials and impressive formats, and some frustration amongst pupils as they want to 'have a go' at using the IWB themselves. Writing on the whiteboard is a slow process, during which time the teacher is not fully facing the pupils. Projecting PowerPoint work or other resources sets up fast paced lessons and greater control of pupils' behaviour. 


\section{Division of Labour}

Within activity theory, it is also necessary to consider the division of labour who does what. In the observations of the lessons, it was clear that more traditional modes of teaching were operationalised. By traditional, we refer to those pedagogical approaches where the teacher assumes a dominant position within the classroom and generally controls the flow of knowledge and questioning. Students often remain passive and work individually.

In the lessons we observed, the teacher had control over the IWB and children were seated on the floor. They were invited to participate in the activity by the teacher. While this model has been seen as outmoded as it does not encourage interaction, it seemed to be a dominant approach when using IWBs. Oridinarily, in such an approach, students are frequently disengaged in the learning process. However, our observations indicated that even though there was a high level of teacher control and minimal student interaction, the children were engaged and on-task with this type of work. This is reinforced by Marcie (below) when she commented on student behaviour.

Marcie: When the kids are all sitting and we are doing with the whiteboard, there are very few behaviour problems. They seem keen to be involved, and very eager to be the one to come to the board. You can see that they are all really wanting to get up the front and have a go. Some of my quiet kids getting really animated when we do the whiteboards whereas in the normal work, you hardly know they are there.

As noted by Marcie in this comment, the roles of the teacher and student seemed to pose a tension between what is often valued in contemporary teaching practices - student-centred activity work - and what was offered by the IWB teacher directed, student passive. The teacher here notes that the students would often be passive in the preferred activity-orientated work but active in the seated IWB work.

A further division of labour can be considered in this environment where digital expertise is featured. While students are often digital savvy, often more so than their teachers, there is also potential for new divisions in digital labour to emerge. Unlike the introduction of computers into classrooms where pupils were likely to have as much if not more expertise than teachers in their knowledge of the computer, pupils do not have access to IWBs. Teachers learn how to use them in training sessions, and are well motivated to do so knowing that they will be 'on show' in front of the pupils. This leads to teachers' ownership of the resource. In contrast, the ordinary whiteboard is owned almost as much by pupils as the teacher. A key outcome of this change in the division of labour, as revealed by the Productive Pedagogies analysis, is that the predominance of the teacher's ownership of the artifact militates against active interactions, open questions and intellectual challenge. Pupils' lack of expertise slows down the pacing, which 
puts at risk the increased motivation of pupils that comes with the IWB. As reported here, the IWB is used almost exclusively for well prepared and presented introduction, followed by individual or group work at their tables or desks. This advance preparation has the same effect, we conjecture, reinforcing teacher ownership and with it a reluctance to open up the use of the IWB into interaction between teacher and learners.

\section{Object/outcome}

Initially the goal for the teacher is to make use of the IWB. The school has decided to buy them and pupils expect to see the latest technology in use, with qualities that at least to some extent match those in their computer games. The teacher is aware of the expectations on her or him to use the IWB. With its introduction comes the knowledge that it captures pupils' attention and engages them immediately on what they see happening, in much the same way as educational television and DVDs has led to increased pupil motivation for those activities. Teachers want to be able to use all the facilities and resources it offers with just a touch of the pointer or finger.

Christian: When overhead projectors came in, we were expected to use them, the same with television, videos, computers. Basically, any new technologies we should be using. Promethean boards are another technological tool that we need to use and show our students. If we don't expose them to new technologies, then we are not meeting our professional responsibilities. It is not so much as to whether the tools might enhance learning or pedagogy but more about exposure to the technologies.

In terms of tensions with the outcome, it would appear that there is some tension between emerging goals for the use of IWBs. While the goal of a lesson or interaction was often framed in terms of mathematical learning or similar, the goal in these new environments is extended to include exposure to new technologies. This is in sharp contrast with the more traditional learning expectations in mathematics lessons.

\section{Community}

Amongst the stakeholders there is often a stated need for the children of the nation to be part of the clever country and for teachers to be at the cutting edge of reforms. However, in contrast to the support offered by the UK government where billions were invested in the use of IWBs, there has been, at best in Australia, rhetorical support but no financial support for the introduction of IWBs.

We conjecture that parents will see the introduction of the IWB as a further distancing of their children's school experience from the parents' own. The shift from the blackboard to the whiteboard is a minor one whereas the IWB has 
significantly changed the classroom. There are likely to be further developments in the same direction in the years to come.

\section{Conclusion}

There is little doubt that IWBs have the potential to enhance learners' opportunities to experience mathematical representations and develop their mathematical thinking. As with all resources, mathematical or other, internalising a tool, be it the number line or a calculator, LOGO, dynamic geometry or graphic calculator, or presentation tools such as overhead projectors or IWBs, transforms the world, in this case of mathematical pedagogy for the teacher. That transformation is always mediated by other experiences. However, as Morgan (1994) pointed out, by themselves tools will not transform pedagogy, no matter what their potential. Indeed, as we have reported in this paper, the technologically impressive features of the IWB can lead to it being used to close down further the possibility of rich communications and interactions in the classroom as teachers are seduced by the IWB's ability to capture pupils' attention. We suspect, also, that teachers' advance preparation for using the IWB, often via the ubiquitous PowerPoint package or pre-prepared lessons for the IWB, means that they will be less likely to deviate from their planning in response to pupils' needs and indeed might notice pupils' needs less frequently through the possibility to increase the pacing of mathematics lessons. Elsewhere (Zevenbergen \& Lerman, 2007) we apply an activity theory framework to try to understand the tensions and contradictions in teachers' use of the IWB and to identify possible developmental trajectories for realising some of their potential to change pedagogy for the better.

What is clear to us from this study of the use of ICTS in general and IWBs in particular, is that technology is mediated by pedagogy. What this study has revealed is that despite the potential and rhetoric of IWB supporters, the ways in which it is used in the classroom may inhibit learning. For the tool to facilitate learning, aspects of the productive pedagogy framework offer ways forward. The two dimensions that focus on knowledge production - intellectual quality and relevance - suggest that the scaffolding around the use of IWBs can be enhanced through higher expectations of learning. The pacing of lessons and the lower questioning levels identified through the interviews suggest that these aspects of pedagogy may be one way in which higher levels of intellectual quality may be facilitated. Aspects of the social environment - supportive school environment and recognition of difference - may also be challenged. The whole class interaction may stifle participation (and engagement) of students. Reorganising pedagogy so as to foster interaction, collaboration in smaller groups, or to employ other tools alongside the IWB may encourage greater interaction among learners. The teacher control at the front of the class may not enable substantive conversations when coupled with the reduction in time in moving between objects. Much like the literature on wait time with questions, these data suggest that teachers may need to adopt similar strategies in terms of pacing to enable students greater opportunities for substantive conversations 
and interactions. Further, the shift of focus from the teacher to students who may be able to take greater control of the technology, may be more enabling for learners.

While there appears to be considerable potential for IWBs to foster new forms of learning, the data in this paper suggest that change is not always easy. Using activity theory to explain the change process enables a means to theorise the difficulties and tensions with the change process. The productive pedagogies analysis provided insights into the pedagogies being used with the IWB environment and a way to classify and identify the degree to which certain pedagogies were employed. These data were expanded through the ethnographic data collected from classrooms as a way to explain the findings.

\section{References}

Armstrong, V., Barnes, S., Sutherland, R., Curran, S., Mills, S., \& Thompson, I. (2005). Collaborative research methodology for investigating teaching and learning: The use of interactive whiteboard. Educational Review, 57(4), 457-469.

Beauchamp, G. (2004). Teacher use of the interactive whiteboard in primary schools: towards an effective transition framework. Technology, Pedagogy and Education, 13(3), 337-348.

Education Queensland. (2001). The Queensland school longitudinal reform study. Brisbane: GoPrint.

Edwards, J.-A., Hartnell, M., \& Martin, R. (2002). Interactive whiteboards: Some lessons from the classroom. Micromath, 18(2), 30-33.

Engestrom, Y. (1999). Activity theory and individual and social transformation. In $Y$. Engestrom, R. Miettinen, \& R-L. Punamaki (Eds.), Perspectives on activity theory (pp. 19-38). Cambridge, UK: Cambridge University Press.

Glover, D., \& Miller, D. (2001). Running with technology: The pedagogic impact of the large-scale introduction of interactive whiteboards in one secondary school. Joumal of Information Technology for Teacher Education, 10(3), 257.

Glover, D., \& Miller, D. (2002). The interactive whiteboard as a force for pedagogic change: The experience of five elementary schools in an English education authority. In Information Technology in Childhood Education (Vol. 1, pp. 5-19). Norfolk: Association for the Advancement of Computing in Education.

Glover, D., Miller, D., Averis, D., \& Door, V. (2005). The interactive whiteboard: A literature survey. Technology, Pedagogy and Education, 14(2), 155 - 170.

Griffenhagen, C. (2000). A report into whiteboard technologies: A published report. Oxford: Computing Laboratory.

Jones, S., \& Tanner, H. (2002). Teachers' interpretations of effective whole-class interactive teaching in secondary mathematics classrooms. Educational Studies, 28(3), 265-274.

Latane, B. (2002). Focused interactive learning: A tool for active class discussion. Teaching of Psychology, 28(1), 10-16.

Leont'ev, A. N. (1981). The problem of activity in psychology. In J. V. Wertsch (Ed.), The concept of activity in soviet psychology (pp. 37-71). Armonk, NY: Sharpe.

Lerman, S., \& Zevenbergen, R. (2006). Maths, ICT \& pedagogy: An examination of equitable practice across diverse settings. In J. Novotná, H. Morová, M. Krátká, \& N. Stehliková (Eds.), Proceedings of the 30th conference of the International Group for the Psychology of Mathematics Education (Vol 4, pp. 49-56.). Prague, Czech Republic: PME.

Maor, D. (2003). The teacher's role in developing interaction and reflection in an on-line learning community. Educational Media International, 401(1/2), 127-138. 
Morgan, C. (1994). The computer as catalyst in the mathematics classroom? In S. Lerman (Ed.), Cultural perspectives on the mathematics classroom (pp. 115-131). Dordrecht, The Netherlands: Kluwer.

Newmann, F., \& associates. (1996). Authentic achievement: Restructuring schools for intellectual quality. San Fransisco: Jossey-Bass.

Schmid, E. C. (2006). Investigating the use of interactive whiteboard technology in the English language classroom through the lens of a critical theory of technology. Computer Assisted Language Learning, 19(1), 47 - 62.

Smith, F., Hardman, F., \& Higgins, S. (2006). The impact of interactive whiteboards on teacher-pupil interaction in the National Literacy and Numeracy Strategies. British Educational Research Journal, 32(3), 443 - 457.

Wall, K., Higgins, S., \& Smith, H. (2005). "The visual helps me understand the complicated things": Pupil views of teaching and learning with interactive whiteboards. British Journal of Educational Technology, 36(5), 851-867.

Waycott, J., Jones, A., \& Scanlon, E. (2005). PDAs as lifelong learning tools: An activity theory based analysis. Learning, Media \& Technology, 30(2), 107 - 130.

Zevenbergen, R., \& Lerman, S. (2007). Pedagogy and interactive whiteboards: Using an activity theory approach to understand tensions in practice. In K. Beswick \& J. Watson (Eds.), Mathematics: Essential research, essential practice (Proceedings of the 30th Annual Conference of the Mathematics Education Research Group of Australasia, Hobart, Vol. 2, pp. 853-864). Adelaide: MERGA.

\section{Authors}

Robyn Zevenbergen, Mt Gravatt Campus, Griffith University, Nathan, QLD 4111, Australia. Email: <r.zevenbergen@griffith.edu.au>

Steve Lerman, London South Bank University, 103 Borough Road London SE1 0AA, United Kingdom. Email: <lermans@lsbu.ac.uk> 